\title{
The Value of Cultural Text Emerges from the Perspective of Media Integration
}

\author{
Guifu Li, Can Li, Ying Shi \\ Shanghai Publishing and Printing College, Shanghai, China \\ Email: 65294056@qq.com
}

How to cite this paper: Li, G. F., Li, C., \& Shi, Y. (2020). The Value of Cultural Text Emerges from the Perspective of Media Integration. Open Journal of Social Sciences, 8, 222-228.

https://doi.org/10.4236/jss.2020.86019

Received: May 9, 2020

Accepted: June 12, 2020

Published: June 15, 2020

Copyright $\odot 2020$ by author(s) and Scientific Research Publishing Inc. This work is licensed under the Creative Commons Attribution International License (CC BY 4.0).

http://creativecommons.org/licenses/by/4.0/

\section{(c) (i) Open Access}

\begin{abstract}
The integration of media is the integration of consumers' rights. The content of media products is affected by knowledge culture and business culture. With the development of the Internet, the transmission of knowledge and culture is becoming more and more fragmented and mobile. The initiative of participation constructs the content of integrated culture, and empowers the rights of participants, which results in the compensatory satisfaction of cultural values. Based on the perspective of the development of media integration, this paper seeks to find out how cultural values emerge in the information channels and mobile communication content across the media. Based on the perspective of the development of media integration, this paper seeks to find out how cultural values emerge in the information channels and mobile communication content across the media.
\end{abstract}

\section{Keywords}

Media Integration, Cultural Text, Value Emerging

\section{Introduction}

With the continuous development of media technology, all kinds of media information are gathered together. Many new media are committed to building a powerful platform for the production and dissemination of content products. Traditional media and new media are also doing all-round grafting. Under the multi-channel integration of media, special websites and mobile applications are set up to design and beautify the interface of media terminals, so that users can easily walk through the media channels and have a good use experience. For more and more users, media usage habits are also changing. People choose media tools according to different environments. The continuous integration of technology brings about a trend, that is, the integration of culture. McLuhan is 
known as the pioneer in the field of media research, but what we need to think about is his theory, not only to study the media content but also to study its own logical method in the media system. This logical method determines how the media is used and its influence on society. Of course, among McLuhan's many theories, what he emphasizes more is that the media with technology is using most of the rights, and the rights of consumers are very small. Henry Jenkins, an American communication scholar, defines the integrated culture as "the cooperative production of meaning and knowledge, and the sharing of problem-solving, which all happen naturally around the common interest when people participate in the network community." (Jenkins, 2015). But from the author's observation, the integration of media is just the integration of consumer rights. When consumers and audiences accept these new technologies, the media function can be developed and expanded. Many articles on media convergence focus on the bearing technology of media. Based on the perspective of the development of media integration, this paper seeks to find out how cultural values emerge in the information channels and mobile communication content across the media.

\section{The Initiative of Participation Constructs the Content of Integrated Culture}

The arrival of the era of media integration we are talking about should include two aspects: one is the integration of technology; the other is the integration of culture. Today, with the development of Internet, the push of all contents of traditional TV media and new media, no matter the program or brand, or even the guidance to consumers, is accomplished through various media platforms. A poster printed with stars and endorsements is published on the Internet from the computer of media producers. It appears on the audience's mobile phones and computers. It is printed on the outdoor advertising wall and broadcasted in the TV network. In a short time, it can be covered in a large range, reflecting a kind of technical integration. The new media technology greatly reduces the cost of production and distribution, exaggerates the channels of content bearing in the way of unlimited windows, and makes it easier for consumers to obtain high-quality content for comments, processing and dissemination. Some scholars and media people are worried about the loss of control of traditional TV media or the excessive use of media products, even more afraid to see a media portal without gatekeepers. These concerns are also worthy of further discussion.

Media products appear in different media terminals, which is certainly not the best effect of communication, but more importantly, a kind of circulation, which needs the participation of consumers or audiences to complete. Participation initiative is the biggest difference between passive watching behavior and unidirectional output in traditional TV media. Participation affects the traditional consumption habits and reconstructs the division of economic benefits of media platform. For example, when the traditional TV media integrates new media, the fans effect is explosive and geometric. In addition to watching and spreading the contents of TV programs, fans will further produce and produce their own cul- 
tural texts and consumption patterns. It's not hard to find that there are many loyal TV program fans in the microblog and forum on the Internet who have set up special sections to discuss the program topics they are interested in, use software to synthesize creative posters, and even re cut the clips of the program content, create their own videos to share with others, and pay attention to and purchase related products. The author takes this kind of participants into consideration Form is the content application of culture integration. Of course, this kind of participation builds an important value sharing bridge between traditional TV media and new media. This bridge is also a shared resource for fans to communicate with each other. As if, in the phenomenon level reality TV show super girl, people have formed a lot of discussions and made a lot of shared comments. "These works constitute a shared myth that we can use to explore our values, our identity and our expectations for the future (Jenkins, 2015). So, fusion is not only based on media equipment, but also on the audience, precisely the interaction of consumers. This kind of interaction, discussion and exchange of information and effects is being valued by the media and businesses, because it is changing the technology, market, industry, pattern and ecology of the media. The spread of integrated culture endows participants with new rights.

\section{The New Rights of Participants Are Empowered in the Context of an Integrated Culture}

This kind of behavior of processing TV programs on the Internet for personal purposes will certainly arouse the attention and discussion of TV media producers on intellectual property rights. From the perspective of the influence of TV programs, traditional TV media still have the right to set agenda to a large extent. In the network, whether fans or grassroots producers, the processing, production and communication of TV programs are mostly based on creative expression. They use the material of the program to make products with personal preferences. In response to this situation, more and more media producers begin to use legal means to protect the transmission of TV programs and control the production of speech. Of course, this discussion and attention in intellectual property reflects the changes in the media environment. More and more people have crossed the legal boundary in obtaining content products and responding to mass culture.

The content of media products is influenced by knowledge culture and business culture, but knowledge culture can play a subtle role in commodity trading. With the development of Internet, the transmission of knowledge and culture becomes more and more fragmented and mobile. The audience also presents the characteristics of rebranding predicted by McLuhan. This rebranding has led to the emergence of new communities, which are divided by the spontaneous and temporary alliance of the audience. They use knowledge sharing and group discussion to connect. In reality TV programs, the audience is eager to know the development of TV plots, but the unpredictability of reality TV programs makes the audience experience the fun. So when the audience starts gathering and 
mining the information and dynamics related to the program, the knowledge community will naturally form, and the type of knowledge community based on Internet technology is what we often experience. In this process, the production and use of cultural knowledge become more grassroots and peaceful, and participants have a new kind of rights in such community space.

In terms of the introduction and output of TV programs, many countries, like China, seem to have the same concerns that other countries or the Internet will bring about a kind of cultural imperialism. Of course, this mutual penetration and reference can also be a way to strengthen cultural communication. What we are looking forward to most is, of course, the reverse flow of culture, so that foreign audiences and fans can understand China through the output of TV programs. Especially in the digital media developed today, the eastern and Western audience more in-depth discussion of each other's hot spots.

For example, in the nearly 10 years of rapid development of TV programs in the TV media, China's mainstream values are changing rapidly, and the pursuit of economic interests has gradually weakened the traditional moral standards. Standards of conduct and values are being squeezed. In the past, the mainstream media, which used to hold the right of discourse, has been pursuing the "mouthful" communication, which makes most of the audience unable to participate in the public discourse. However, in the 1990s, reality TV programs appeared in the traditional TV media, which provided a stage for the audience to show their strengths, express their ideas, and even "grassroots counter attack". The people get an emotional catharsis, indulgence, to meet the inner fantasy. After 2010, with the large amount of private capital entering, the development of TV programs is no longer limited to the grass-roots class. The programs show the unknown side of stars with a kind of entertainment design and life language. Of course, this kind of show of stars still confuses the true of mimicry and the true of reality, but this kind of true and false performance also satisfies the audience's private psychology. Different from the programs that Chinese stars participate in, most of the TV program participants in Europe and America are ordinary people. Their program environment pays more attention to the setting of rules. By strictly implementing the competition system of the competition, some aspects of human nature are inspired. The end of the competition is attracted by huge bonuses. In the competition, the good and evil of human nature are displayed all the time. The audience can also experience the competition, cooperation, good and evil while watching. Finally, the grass roots win millions of awards and complete the counterattack of life. This kind of snatch of the public discourse right and the magnifying and peeping of personal privacy is also a kind of portrayal of network culture. In the virtual space, people blur the real social identity, narrow the gap of social status, and use the carnival on the keyboard to satisfy the inner fantasy. Therefore, whether it's mimicry or reality, this kind of prying into other people's lives and the illusion of life are vividly displayed in TV programs and online programs. 


\section{Integration of Culture Makes Participants Produce Compensatory Satisfaction of Cultural Value}

Up to now, the Internet is considered to be the most daily happy industry. Most of the public surf the Internet for recreation and entertainment. Entertainment means nodding that the cultural industry has turned entertainment into belief and purpose. Its power is just played through entertainment. Internet culture takes mass culture as its coat, but in essence the mass is in the subordinate position of being dominated and enslaved. Although the cultural industry itself must adapt to the mass to exist, the mass is not the measure of the cultural industry itself, but its ideology (Adorno, 2011). under the illusion of pleasure and satisfaction, cyberspace transmits the consciousness of locking handcuffs, and realizes the upgrading of control means relying on advanced technology.

With the development of science and technology, relying on 5G technology and big data technology, the development of entertainment industry can achieve the goal of taking every individual as a node, starting from the interests and needs of the power class, making use of the "nonautonomous state" that can't be extricated by the atomic popularization of individuals, and more deceptively cultivating the false needs and inhibitory needs; making use of the developed self-Media and open literature To make the product production port, share the production process, power and ability, let the individual produce the illusion of initiative and creative participation, and achieve the purpose of participatory and involved control; to use the user's dream for themselves, as well as the desire to experience the upper social life, through "identification" and "kitsch", realize the poor model of the ideal world in the virtual space imitation (Hokheimer, 2006).

Over the years, traditional TV media and network media have developed in parallel. Many scholars want to use Bakhtin's "Carnivalization" as their footnotes. Crazy experience, enthusiastic audience, hard-working host, thrilling game "This kind of technical arrangement essentially caters to the needs of constructing carnival, because in carnival, all people are not as spectators, but active participants, to participate in carnival." So with the integration of media, the TV screen has been broken, this carnival has entered the real life, the audience can participate in all kinds of mobile terminals at any time. The real interaction of "Pseudo Environment" in TV is in the real life. For example, the current reality TV program is different from the early stage, and the means of processing is more and more westernized. Due to the difference of cultural background, the reality TV programs in Europe have just blurred the concept of the show through the treatment of TV language, breaking the boundary between "simulacrum" in TV and "truth" in life. Of course, this is a superb TV production skills is also a manifestation of cultural heritage, through this clever discretion and inspiration, TV producers can easily exit from the TV screen without leaving traces. However, in the transplanted reality TV programs, due to the hard copy of the "classic" or the hands of the program developers, but due to the differenc- 
es in production level, concept, technology and cultural thought, TV producers or participants in the "show" are easy to confuse the pseudo truth with the real truth. And this kind of real life is exactly the reflection of network life. The virtuality of the network lies in that all the words, pictures and videos we see are presented through selection, processing and reconstruction. But people often don't realize this pseudo environment, but treat it as an objective environment. "We must pay special attention to a common factor, that is, a pseudo environment is inserted between man and his environment, and his behavior is a response to the pseudo environment," Lippmann said. But just because this kind of response is a real behavior, its result does not affect the pseudo environment that stimulates the behavior, but the real environment in which the behavior actually occurs. "When the Internet and reality TV show are combined, great chemical reactions will often occur. In the Internet world, most people's identities are virtual. Gender, age and social status can be erased or processed. Everyone talks in the Internet world with a potential personality. This kind of dialogue breaks the limit of social distance, and even the netizen can speculate, observe, talk and deny anything he is interested in. In the programs that stars participate in, the performance under the pseudo environment will be mapped in the network society, whether it is true or not, it will be supported or opposed by a large number of netizens. This kind of power will be projected into the real society, which will have an impact on the life or work of the participants of the reality show.

TV media has a strong role of entertainment, but also has a strong role of cultural orientation. But the impact of economic thought also forms a kind of cultural reference in the cultural aspect. This kind of nationalization and localization has shown a weakness in cultural reference. When American TV producers produce survivor, they always use TV language to strengthen the "American spirit". Freedom, competition, adventure, dream. This is in line with the appreciation psychology and need of American TV audience, in fact, it is a kind of localization transformation. But if you make or introduce survivor in China.

\section{Conclusion}

The application of Internet technology and new media technology brings great challenges to traditional TV media, but at the same time, it also provides more development opportunities. The integration of media not only brings about the change of mode, concept and mode, but also a change of marketing method, management mode and strategic deployment, and also gives birth to a new media ecology and market pattern. As American scholar Jenkins said, the integration of media takes place in the mind of consumption rather than in a box. Even though media technology is not fully integrated, our body and brain are already using media in an interrelated way. The most important integration for consumption or audience is also reflected in cultural integration. Audiences with subjective initiative and strong productivity will produce their own cultural texts and consumption patterns after watching media products. 
The content of media products is influenced by knowledge culture and commercial culture, but knowledge culture can play a subtle role in commodity trading. With the development of Internet, the transmission of knowledge and culture becomes more and more fragmented and mobile. Cultural communication is dynamic here. Both encoding and decoding are bidirectional. Up to now, with the development of multi screen, the Internet has been fully socialized, completed the interactive communication between people, and maximized the communication between people and social coordination. The reason for maximization is to maximize the development, transfer and functional configuration of human fragmented time, idle physical intelligence and redundant resources. The emergence of multidimensional space is to activate these resources, use everyone's "hot spots" to form a three-dimensional space through the Internet platform, where the information is interactive and circulating, and can form observation, speculation and so on through any time point and space. Under the condition of media integration, the traditional media content must also be in line with the localized appreciation psychology and needs, and the integration of market rules will be a good cultural reference and value emerging.

\section{Acknowledgements}

Supported by 2020 Project of Higher Education Research Institute of SPPC; 2020 Shanghai University Think tank Connotation Construction Project "Shanghai Cultural Brand Construction and Communication in the Context of New Media Application of Narrative Virtual Reality Art in Shanghai Museum (Item Number: YB2019C02); Media Integration Development Research Center and Media Creation Studio of Shanghai SPPC.

\section{Conflicts of Interest}

The authors declare no conflicts of interest regarding the publication of this paper.

\section{References}

Jenkins, H., \& Du, Y. M. (2015) Fusion Culture-Conflict Zone between New Media, Good People and Old Media (2015 Edition, p. 10). Beijing: Commercial Press.

Adorno, T. (2011) Cultural Industry (Translated by Zhao Yong, pp. 42-46). Guiyang: Guizhou Social Science.

Hokheimer, M., \& Adorno, T. (2006) Dialectics of Enlightenment (Translated by Qu Jingdong and Cao Weidong). Shanghai: Shanghai Century Publishing Group. 